

\section{UNIVERSO DIVERSO}

\section{ROGÉRIO PARENTONI MARTINS*}

RESUMO Diversidade é banal no universo. Em nosso planeta, até mesmo o homem mais desatento é capaz de perceber a trivialidade de certos objetos físicos e biológicos. Entender as causas da diversidade é outra história. Há que se ter curiosidade e dúvida, os ingredientes que alimentam a vontade de conhecer. Não basta a vontade, todavia, sem que haja teorias a orientar os procedimentos necessários para se obter conhecimento científico. Não que esse conhecimento seja superior aos demais conhecimentos populares; é diferente apenas. A diferença é a de que cientificamente não podemos confiar em nossos sentidos para entender problemas complexos. A teoria nos possibilita abstrair-nos da avalanche de informações que recebemos visualmente, para que consigamos captar a simplicidade subjacente a fenômenos que nos pareçam complexos. A complexidade dificilmente será compreendida por meio de teorias ou modelos complexos. Felizmente podemos esperar soluções simples e generalizáveis que podem ser obtidas pela análise de um determinado fenômeno que se expressa por meio de ocorrências padronizadas em escalas de tempo e espaço. A ocorrência e distribuição da biodiversidade em nosso planeta se expressa por meio de padrões. Detectá-los é o primeiro passo para entendê-la. Em seguida, é necessário investigar quais são as causas responsáveis pela expressão do padrão observado.

Palavras-chave Biodiversidade. Complexidade. Simplicidade..

\section{DIVERSE UNIVERSE}

ABSTRACT Diversity is trivial in the universe. Even the most casual observer is able to perceive the triviality of certain physical and biological objects. Understanding the causes of diversity is a completely different matter. Curiosity and doubt are the ingredients that feed the will to know, though will is not enough: it must come along with theories to guide the acquisition of scientific knowledge. Not that this knowledge is superior to common sense; it is just different. The difference is that we cannot trust our senses to understand complex problems from a scientific perspective. Theory allows us to refrain from the torrent of information we receive visually so that we can capture the simplicity underlying the phenomena that seem complex. Complexity is hardly understood through theories or complex models. Fortunately, we may expect simple solutions and generalizations that can be obtained by the analysis of a particular phenomenon expressed through similar occurrences, which are repeated at different spatial and temporal scales. The occurrence and distribution of biodiversity on our planet is expressed through patterns. The description of such patterns is the first step to understand biodiversity. Then it is necessary to investigate which factors are responsible for these expressed patterns.

KEYWORDS Biodiversity. Complexity. Simplicity..

* Prof. Visitante-Senior, Programa de Pós-Graduação em Ecologia e Recursos Naturais da Universidade Federal do Ceará. Pós-Graduação em Ecologia, Conservação e Manejo de Vida Selvagem, Instituto de Ciências Biológicas da Universidade Federal de Minas Gerais.

E-mail: rpmartins917@gmail.com

Recebido em 19/10/2015. Aprovado em 21/03/2016. 


\section{Introdução à simplicidade}

experiência sensorial humana mais expressiva é a de constatar a diversidade em
todos os objetos do mundo. Até mesmo o olhar mais desatento, de alguma forma, reconhecerá a diversidade em um conjunto de objetos aparentemente semelhantes. Diversidade é trivial; ocorre em todo o universo. Não poderíamos esperar que fosse diferente, dado que evolução é mudança. Mudar não significa descartar opções anteriormente expressas, ao contrário do que observamos na evolução do universo, e vida é uma tendência à complexidade. Entenda-se complexidade como acúmulo de estruturas geometricamente sofisticadas criadas com componentes simples. Entender complexidade é uma tarefa longe de ser trivial. Por isso, não surpreende que haja uma ciência da complexidade (Holland, I996). A expectativa dos estudos sobre complexidade é a de compreender como ela se origina, como evoluiu e se mantém graças ao arranjo espaço temporal de suas configurações estruturais simples (building blocks, na expressão de Holland, I966). A hipótese sobre a manutenção da complexidade que evoluiu é a de que essa condição em si produz estabilidade do sistema complexo. Aplicado à biodiversidade, podemos esperar que quanto mais complexa for a estrutura de uma comunidade biológica, menos possibilidade há de a extinção de uma espécie particular não causar a extinção de todas as espécies da comunidade. Algumas espécies são funcionalmente redundantes; se uma delas for extinta, haverá outra que cumprirá função equivalente, mantendo a integridade do ecossistema durante certo intervalo de tempo (Naeem, I998).

Em geral, ecossistemas ou comunidades mais biodiversos serão mais estáveis com relação aos efeitos desagregadores de eventuais distúrbios. A biologia é repleta de exceções, inclusive para a generalização citada. Uma espécie predadora topo de cadeia alimentar, introduzida em uma comunidade diversa, poderá drasticamente reduzir a diversidade, desfazendo as interações de integrantes da teia alimentar. A introdução do peixe predador voraz, Cicla ocelaris (tucunaré), no lago artificial Gatún, Panamá, provocou um efeito devastador sobre estrutura da comunidade após levar espécies de outros peixes à extinção local. (Zaret; Paine, I973). Mexilhões em costões rochosos ocupam a maior 
parte do espaço disponível e reduzem a diversidade local. Quando predados por uma estrela do mar, a disponibilidade espacial de fixação para outras espécies aumenta. Ocorre o aumento da diversidade por meio da predação sobre o competidor que é mais eficiente em ocupar o espaço nas rochas (Paine, I966). Os exemplos de campo mais convincentes sobre a possibilidade de aumento ou diminuição da biodiversidade local derivaram de comunidades simplificadas. Comunidades complexas, tais como as de floresta tropical, são empiricamente mais resistentes a esse tipo de demonstração experimental, mesmo se há grande conjunto de dados disponíveis. Há exceções, como a do estudo sobre interações entre espécies vegetais e animais em uma floresta tropical, tendo por base espécies-chave que conectam diferentes níveis tróficos em teias alimentares coevoluídas. O modelo é simples, baseado nas atividades das espécies-chave polinizadoras e dispersoras de sementes indispensáveis para manter a diversidade da floresta (Gilbert, I980). A previsão é a de que se essas espécies-chave forem extintas, a floresta se desestruturará por meio de uma cascata de extinções locais ou por falta de recrutamento das espécies vegetais. Trata-se de um modelo baseado em observações naturalistas.

A notável capacidade atual de armazenamento, análise e integração de numerosas evidências sobre fenômenos complexos possibilita a síntese de grandes quantias de dados. Mesmo com essa facilidade, deve-se evitar elaborar modelos muito complexos. Modelos desse tipo muitas vezes resistem a interpretações simples. Em decorrência, a explicação de fenômenos complexos é refratária a modelos que também sejam complexos. Em outras palavras, complexidade se entende por meio de simplicidade.

Os físicos são bem-sucedidos na formulação de modelos matemáticos simples em níveis macrocósmico e microcósmico. A aplicabilidade de alguns desses modelos incide sobre a vida cotidiana, o que lhes dão credibilidade e legitima suas descobertas. Porém, referente ao aspecto preditivo sobre consequências complexas de eventos simples, é embaraçoso que previsões precisas sobre os resultados de tais eventos não sejam obtidas. Considere uma taça de vinho de cristal vazia que acidentalmente caia de uma altura de Im. É realizável prever-se o número e o tamanho de cada fragmento resultante do impacto da queda? "Presentemente, é possível avaliar a distribuição estatística de tamanhos de fragmento (número de fragmentos com certo tamanho). O tamanho de um fragmento em particular é impossível ser previsto" (J. M. Figueiredo, Dep. Física da UFMG, comunicação pessoal). O físico sequer menciona a possibilidade de avaliação da forma dos ca- 
cos da taça, o que me levar a imaginar que se um tamanho linear particular, mais simples de ser medido, é impossível de ser previsto, sua forma deve ser inconcebível.

Embora conhecimentos da biologia também repercutam na vida cotidiana (e.g., determinação da paternidade), os fenômenos biológicos expressam uma variabilidade em nível muito superior àquela resultante do comportamento de objetos físicos. Em qualquer parte do universo conhecido, um átomo é estruturalmente idêntico e se comporta como qualquer outro átomo tomado ao acaso. Muitos fenômenos biológicos têm influências multivariadas. Se considerarmos um indivíduo ou uma célula como unidade de estudo, constataremos que esse indivíduo em uma mesma população é distinto dos demais, incluindo gêmeos idênticos. O mesmo raciocínio aplica-se a uma célula. Todas têm uma estrutura básica comum, porém formas, tamanhos e comportamentos distintos.

Há sempre expectativas em encontrar simplicidade subjacente à complexidade. Descobri-la e expô-la com elegância é uma das metas importantes e criativas de um cientista, ou seja, formular teorias que captem a realidade (veja Martins, 2002). Como posso saber se uma teoria capta a realidade? Uma das formas é a de testar empiricamente as previsões que podem ser extraídas da estrutura da teoria. Testadas contra o "background" empírico, estas devem ser corroboradas ou não pelos resultados das observações ou experimentos. Caso isso não aconteça, pode ser que a estrutura da teoria utilizada requeira revisão. Às vezes, um conceito apenas é necessário ser adicionado à estrutura da teoria para que suas previsões se cumpram empiricamente (veja Pickett. et al., 2007).

O código genético é notável exemplo de simplicidade. Constituído de 22 aminoácidos apenas, as combinações entre eles podem chegar a várias ordens de magnitude, suficientes para expressar toda a biodiversidade. As múltiplas ordens de magnitude das combinações dessas estruturas moleculares simples resultam em espantosa variabilidade de formas, tamanhos e comportamentos.

Mutação genética, seleção natural, recombinação e fenômenos epigenéticos (Laland, et al., 20I4) são os principais eventos responsáveis pela origem e evolução da biodiversidade. Biólogos, que raramente discutem a estrutura teórica da teoria de evolução por meio de seleção natural, acostumaram a repetir que evolução não é mais teoria apenas, mas fato. Concordo em parte. Evolução é simplesmente mudança, e, porque tudo no universo muda, evolução não se refere especialmente à biodiversidade 
apenas. O que interessa em ecologia é entender como e por que essa mudança ocorre. A estrutura teórica neodarwinista prevalece como o sistema de teorias mais adequado para explicar a origem e diversificação da vida, no passado e presente. Atualmente, os neodarwinistas deverão reconhecer que, durante o processo de desenvolvimento de um indivíduo, alterações não mutacionais na estrutura do DNA, ou na cromatina, serão transmitidas à próxima geração. Tais alterações epigenéticas são coadjuvantes da seleção natural em operar mudanças evolutivas.

Cientistas, que dedicaram toda uma vida a defender e mostrar a abrangência de uma teoria em biologia, às vezes, têm dificuldades em aceitar a sua limitação explicativa decorrente da variabilidade. A história da ciência é farta em exemplos desse tipo de resistência (não apenas na biologia), em especial quando a estrutura da teoria alternativa proposta ainda é pobre em evidências. Um exemplo recente diz respeito aos que defendem o arcabouço teórico do neodarwinismo apenas como necessário e suficiente para entendermos a origem e diversificação da vida. A discordância dos neodarwinistas com os que defendem a incorporação da epigenética ao sistema de teorias evolutivas é radical. A maioria recusa entendimentos que não se fundamentem em genética, ecologia e evolução, embora haja evidências da transmissão de modificações fenotípicas para novas gerações. (Laland, et al., 20I4; Wray, et al., 20I4). Quaisquer esforços em aprimorar teorias, a bem do avanço do conhecimento, devem ser reconhecidos. A controvérsia genética versus epigenética ainda irá se esclarecer; a questão é mais sobre o quantitativo do que a respeito do qualitativo.

Espacial e temporalmente, a diversidade se distribui do universo do infinitamente amplo ao universo do infinitamente restrito (Oliveira, 2002). O primeiro pode ser reconhecido por meio de subconceitos hierarquicamente alinhados. Os subconceitos referentes a cada concepção singular dessa hierarquia se encaixam como matrioscas, as bonecas russas de madeira. O macrocosmo inclui aglomerados de galáxias, galáxias, sistemas solares (estrelas em torno das quais planetas e satélites orbitam), meteoroides (fragmentos de materiais vagantes no espaço) meteoros (um que penetra na atmosfera de um planeta), meteoritos (quando um meteoro atinge a superfície de um planeta), asteroides (estruturas rochosas e metálicas que orbitam ao redor do sol) e cometas (estruturas cujo núcleo é composto de gelo, poeira e pequenos fragmentos de rochas). Alguns podem apresentar caudas. Por sua vez, o microcosmo é organi- 
zado em padrão semelhante ao macrocosmos, em unidades infinitamente pequenas do átomo a várias partículas subatômicas.

Houve 28 grandes eventos marcantes na história do universo e da vida (Morowitz, 2002). Há cerca de I2,5 bilhões de anos aconteceu o “Big Bang”. O macrocosmos inicialmente caótico se auto-organizou. Emergiu a tabela periódica e outras etapas de organização e complexidade antes que os cordados evoluíssem e, posteriormente, os mamíferos. Estes se diversificaram até os grandes primatas e o homem. A evolução do homem fez emergir a consciência e cultura. A autoconsciência proporcionou ao homem reconhecerse e diferenciar-se dos demais objetos do universo. Muito recentemente, do ponto de vista do tempo geológico, há cerca de 2.000 anos, na Grécia antiga, foram estabelecidas as bases filosóficas do conhecimento ocidental. A ciência nasceu vinculada à filosofia como irmãos siameses unicórdios. A física era denominada filosofia natural e como a biologia contemplava-se e refletia sobre a natureza do mundo físico e biológico, como o fez Aristóteles. No renascimento, movimentos filosóficos e científicos propuseram o apartamento da ciência da filosofia. Contemporaneamente continua a filosofia apartada da ciência. Tenho dúvidas se essa desvinculação foi melhor para o incremento do conhecimento do que se continuasse ligada à filosofia. Hoje a filosofia da ciência cuida de discutir sobre a validade do conhecimento científico, entre outras questões. O conhecimento sobre a biodiversidade passa pelo crivo da filosofia da ciência no tocante à validade do conhecimento sobre as causas da diversificação da vida, até mesmo sobre o que é vida (Coutinho et al. 2007). Paradoxalmente, os biólogos estudam vida, mas não há consenso sobre o que vida é, haja vista a quantidade de definições (veja em Luisi, I998, discussão sobre várias definições do conceito vida).

\section{Terra: planeta peculiar}

Nosso planeta é peculiar pelo fato de nele ter-se desenvolvido vida. Na superfície do planeta, a vida diversifica-se em formas, tamanhos e comportamentos variados. Por que há essa diversidade de formas, tamanhos e comportamentos? Boa parte da resposta está na seleção natural e evolução que ocorrem em ambientes geológica e espacialmente diversos (montanhas, vales, morros, planícies cortadas pelos rios, 
oceanos e mares). Em diferentes escalas espaciais, essa diversidade de estruturas geológicas pode atuar como barreiras ao fluxo migratório de espécies. Espécies isoladas por meio dessas barreiras integram comunidades peculiares. Em isolamento extremo, podem evoluir espécies endêmicas (somente ocorrem em determinadas áreas geográficas restritas) que exibem adaptações bizarras. As cordilheiras dos Andes e os Himalaias são enormes barreiras intransponíveis para muitas espécies. Populações dessas espécies se diferenciam em formas, tamanhos e comportamentos distintos resultantes das diferentes condições ecológicas sob as quais evoluem. Imagine um corte ortogonal que retire um naco da Terra, semelhante a um disco tridimensional. A imagem resultante do corte revelará a distribuição heterogênea e contínua da biodiversidade a partir dos $5.000 \mathrm{~m}$. abissais aos $8.848 \mathrm{~m}$ cuminantes do Everest, as amplitudes extremas de ocorrência de vida.

Cada região geográfica neste gradiente de diversidade compõe-se de biomas. Grosso modo, estes podem ser diferenciados por meio da fisionomia da vegetação. A fisionomia transmite impressão de homogeneidade, como a floresta atlântica e os cerrados brasileiros vistos de cima. A homogeneidade não resiste, sobretudo, a uma análise mais detalhada, que revelará heterogeneidade (variações horizontais) e complexidade (variações verticais ou estratos distinguíveis da vegetação).

Os biomas abrigam ecossistemas e comunidades, conjuntos de plantas, animais, e microrganismos que interagem por meio de redes de interações, muitas delas coevoluídas (Thompson, 20I2). Não apenas número em espécies e suas abundâncias relativas, mas também redes de interação, número de interações de cada espécie na rede são modos de se expressar a complexidade da biodiversidade em comunidades. Esta pode ser representada alternativamente por pirâmides alimentares, nas quais os organismos são arranjados em no máximo seis níveis tróficos sucessivos. Uma das razões para que não tenham evoluído organismos em um sétimo nível trófico é a de que parte da energia que percorre os níveis tróficos dissipa-se em calor metabólico não aproveitável para a produção de biomassa. Quando a energia chega ao sexto nível trófico, a perda foi tão grande que, além desse limite, não haverá energia disponível para produzir biomassa.

Comunidades incluem assembleias (conjuntos de organismos em uma mesma categoria taxonômica), por exemplo, pássaros dos cerrados. Espécies de diferentes assembleias podem ser agrupadas em guildas (conjunto de espécies de categorias ta- 
xonômicas diferentes que utilizam da mesma forma o mesmo tipo de recurso (e.g., pássaros e morcegos frutívoros ou pássaros e morcegos insetívoros em uma reserva florestal urbana). Em todas essas categorias, as populações são unidades operacionais relativamente mais simples e fáceis de ser estudadas. A forma mais simples de se medir a diversidade, nesses níveis mais complexos de organização, é a de contar o número de espécies e as abundâncias relativas de suas populações. Outras medidas relacionadas às demais categorias mencionadas requerem procedimentos um pouco mais sofisticados. Refiro-me, por exemplo, a medir produtividade primária bruta (quantidade de matéria orgânica produzida em gramas, durante certo tempo em um espaço determinado, por uma população ou comunidade por meio da fotossíntese) e produtividade secundária (quantidade de matéria orgânica ingerida, menos o que não é assimilado e eliminado pelas fezes, urina e gases, menos o que é perdido por meio da respiração) como modo de caracterizar a diversidade de ecossistemas, ou a variedade de habitats verticais (estratos) em uma floresta como medida de complexidade. Descrever uma floresta por meio do discernimento de seus extratos verticais, além de indicar complexidade estrutural da vegetação, serve para caracterizar a diversidade em espécies que ocupam preferencialmente cada estrato (MacArthur, I958). Em outro extremo estariam assembleias de gramíneas distribuídas em amplas extensões espaciais, a exemplo do Parque do Serengueti (grandes planícies na linguagem Masai). O parque, situado na África oriental, ocupa $40.000 \mathrm{~km}^{2}$ dominados por um único estrato vertical de gramíneas, mas com heterogeneidade expressiva em virtude da diversidade de espécies. A biomassa expressiva de gramíneas (alta produtividade primária líquida) mantém uma biomassa colossal de ungulados pastejadores, os quais migram na mesma medida da escassez das gramíneas, provocada pelo pastejo intenso das áreas utilizadas) e expressiva diversidade de felinos e canídeos (produtividade secundária) que acompanham a migração e se alimentam desses pastejadores.

Em trabalho recentemente realizado no Brasil, a diversidade em espécies de peixes de diferentes assembleias fluviais foi comparativamente medida utilizando-se dois tipos de índices de diversidade: Margalef (K) e Shanon (H). O índice de Margalef demonstrou maior consistência e sensibilidade a mudanças na estrutura das assembleias. Além disso, é um bom indicador de diversidade em séries temporais de amostras para indicar mudanças causadas na estrutura das assembleias, por meio de modificações 
antropogênicas. Ainda, é também um bom indicador da velocidade de evolução de um ecossistema (Iglésias-Rios; Mazzoni, 20I4).

Populações humanas em biomas estruturalmente diferenciados são diversas geneticamente (A diversidade genética é neste número abordada por Eduardo Tarazona). Atrelados a essa diversidade biológica (genética e ecológica), os atributos morfológicos, fisiológicos e comportamentais humanos e a diversidade étnica, linguística, poética, musical, plástica também fazem parte da biodiversidade, em especial, se interpretadas como adaptações evoluídas sob condições ecológicas variáveis (Weiss et al., 20I5).

\section{A biodiversidade ecológica: padrões e processos}

As configurações temporal e espacial da biodiversidade podem ser descritas por meio de padrões, e sua dinâmica pode ser compreendida por meio da atuação de processos que os causam. Padrão é a recorrência de um mesmo tipo de fenômeno em tempos ou espaços distintos. Descrever padrões é um modo de se iniciar a compreensão sobre um dado fenômeno. Se um mesmo fenômeno ocorre em diferentes escalas temporais e espaciais, e a amostragem que o caracteriza é aleatoriamente realizada, poderemos dizer se o padrão ocorre ao acaso ou se haverá uma ou mais causas que o produzem. Uma ferramenta geométrica útil para identificar padrões escalares espaciais é a aplicação de fractais. Fractais descrevem superfícies que repetem a mesma forma em escalas diferentes. Imagine a forma das ramificações arteriais e venosas que constituem o sistema pulmonar. Se seccionarmos horizontalmente uma faixa de 3 cm de espessura, constataremos que a secção obtida repete a forma do sistema como um todo, ou seja, o arranjo em escala reduzida é morfologicamente idêntico ao todo. Fractais também podem ser aplicados em ecologia da paisagem a fim de determinar qual seria o padrão identificador da geometria da paisagem (Sugihara; May I990). Atrelados a uma ou mais causas, há processos dinâmicos que originam e mantém os padrões em distintas escalas temporais e espaciais. Processos produzem padrões, por meio das causas que organizam um fenômeno em determinado padrão. Por exemplo: a competição pode produzir um padrão de distribuição regular de ninhos de saúva na época de fundação de ninhos. Em locais onde há ninhos instalados, as fêmeas fertiliza- 
das que tentam estabelecer novos ninhos próximos a eles são mortas pelas operárias. Assim o padrão de distribuição regular dos ninhos é mantido (observação do autor).

Ignoramos a magnitude da diversidade de organismos na Terra. Uma das grandes questões da ecologia é a de estimar, com menor margem de erro possível, o número de espécies que vivem no planeta. Enquanto isso, espécies conhecidas e ainda ignoradas se extinguem, e a formação de novas espécies continua em velocidades variadas. A velocidade de especiação em microrganismos é de várias ordens de magnitudes maior que a de mamíferos. Todos mamíferos herbívoros placentários e marsupiais têm câmaras de fermentação onde há microrganismos. Sem a participação dos microrganismos, esses animais não conseguiriam extrair os nutrientes das plantas das quais se alimentam, o que sugere um papel importante dos microrganismos na evolução de mamíferos herbívoros (Price, 2002). Exemplo de velocidade restrita de especiação é o de nosso gênero Homo, com nove espécies conhecidas (Roberts, 20II). Todas foram extintas, exceto $H$. sapiens sapiens, que domina o período geológico antropoceno (Martini; Ribeiro 2012) - período de algumas centenas de anos apenas, no qual nossa espécie predomina tecnologicamente com uma abundância expressiva. Somos atualmente mais de 7 bilhões de pessoas; em 2050, estima-se que seremos mais de 9 bilhões. Uma só espécie com esse número espantoso de indivíduos!

Alguém poderia argumentar sobre a microbiota ser tão ou mais numerosa que os humanos. Há razões para se pressupor a expressiva diversidade em espécies de microrganismos. Estes têm alta frequência de ocorrência de mutações, tamanho microscópico, tempo de geração curtíssimo, elevadas taxas de evolução (medidas em Darwins, Gingerich, 2002) e capacidade de viver e obter nutrientes, tanto em vida livre como parasitas em células, tecidos e órgãos de invertebrados e vertebrados. Não há única espécie dessas classes taxonômicas que não tenha pelo menos uma centena de espécies de microrganismos associados. A diversidade de microrganismos é muito menos conhecida, por dificuldades práticas e porque a microbiologia desenvolveu-se focalizando em microrganismos causadores de patologias humanas e de animais domésticos. Nos últimos 30 anos, a microbiologia ambiental tem-se desenvolvido a reboque de problemas ambientais, especialmente poluição de águas e solos. Por outro lado, se pensarmos em sucesso de persistência temporal e espacial, os microrganismos que existem pelo menos há 3,5 bilhões de anos dominam a biosfera. 


\section{Biodiversidade brasileira e mundial}

Dezessete países concentram cerca de 60\% da biodiversidade global. Por esse motivo e também por apresentarem um grande número de espécies endêmicas, foram denominados megadiversos (Mittermayer, I998). O Brasil ocupa o primeiro lugar no ranking desses países. Recentemente, Lewinsohn et alii., (2002) sintetizaram o que se conhece sobre a biodiversidade brasileira. Essa síntese minuciosa também chama a atenção para as dificuldades em se produzir estimativas: por exemplo, carência de taxonomistas para alguns grupos, que permanecem sub-representados; distribuição desproporcional de informações taxonômicas entre regiões do país. Para certas regiões, há sequer informações sobre grupos inteiros ou mesmo inventário algum realizado. Apesar disso, os autores citados obtiveram as estimativas de I68.730 a 2I2.740 espécies contra I.697.600 a I.798.500 mundiais. Segundo as estimativas, o Brasil agrega mais de ı०\% da biodiversidade mundial.

\section{A beleza oculta: o papel da teoria}

A beleza das paisagens diversificadas sempre foi, para muitos, motivo de atenção e encantamento. Subjacente à beleza estética das configurações geométricas ou assimétricas dos objetos, há uma beleza oculta a nossos olhares. Sabe-se sobre nossa incapacidade sensorial em perceber detalhes. Às vezes, podemos nos surpreender observando imagens irreais que julgamos reais. Por exemplo: a submersão de um graveto na água límpida de um lago resultará em uma imagem do graveto seccionado. Quando o retirarmos, estará tão íntegro como foi introduzido. Essa limitação de nossa capacidade perceptiva pode ser superada por meio da imaginação advinda da contemplação. Contemplação foi uma das primeiras definições de teoria. A partir desta, outras definições mais operacionais foram propostas, por exemplo. "Teoria é um modelo robusto e suas consequências” (Sugihara; May I990). Embora seja uma definição sucinta, não esclarece o papel que a teoria desempenha para o incremento do conhecimento científico, a não ser talvez para os próprios modeladores. Para os demais, seria necessário definir o que é um modelo robusto e os tipos de consequências de sua aplicação para o conhecimento de fenômenos naturais. 
Independentemente da definição que se queira utilizar, o papel que a teoria desempenha para o conhecimento científico é fundamental para conhecermos como se organizam certos fenômenos que a nossos olhos pareçam irregularidades. Subjacente à irregularidade poderemos encontrar um padrão ordenado e regular por meios dos "olhos" da teoria que utilizamos ou criamos. Holland (I996), citado na introdução, admite uma beleza subjacente à complexidade. Esse tipo de beleza para o pesquisador é a organização ordenada de fenômenos complexos que parecem ser caóticos. Prefiro enfatizar a beleza estética de uma teoria que ilumina a compreensão sobre as possíveis causas responsáveis pela configuração de um padrão. De uma forma ou de outra, as teorias contribuem para reduzir nossa ignorância científica, derrubar mitos e diminuir possíveis aversões e preconceitos sobre fenômenos naturais que nos pareçam ameaçadores.

\section{Agradecimentos}

O editor deste número temático, Francisco Barbosa, convidou-me a escrever o artigo e comentou-o criticamente; Ricardo Iglésias-Rios e Romeu Guimarães também contribuíram para melhoria do texto. Marcos Soares Barbeitos verteu o resumo.

\section{Referências}

ANTUNES, L. C. M. A microbiota humana. Ciência Hoje. 20I4, n. 316, p. 27- 29.

COUTINHO, F. A. et al. Construção de um perfil conceitual para o conceito de vida. Investigações em Ensino de Ciências. 2007. v. I2, n. I, p.II5-I37.

GILBERT, L.E. Food web organization and the conservation of neotropical diversity. In: M. E. SOULÉ; WILCOX, B.A. (eds). Conservation Biology - An evolutionary -ecological perspective. Sinauer Associate, Sunderland, Massachussets, I980.

GIMGERICH, P. Quantification and comparison of evolutionary rates. American Journal of Science, I993, v. 293-A, p. 453-478.

HOLLAND, J.H. Hidden order: how adaptation builds complexity. New York, Helix Books, I996.

IGLESIAS-RIOS, R \& MAZZONI, R. Measuring diversity: looking for process that generate diversity Natureza \& Conservação. 20I4. v. I2 n. 2, p. I56-I6I. 
LALAND, K. et al. Comments. Nature , 20I4, v. 5I4, p. I6I-I64.

LEWINSOHN, T. M.; PRADO, P. I. Biodiversidade Brasileira: síntese do estado atual do conhecimento. São Paulo Editora Contexto, MMA, Conservation International do Brasil, 2002.

LUISI, P.L. About various definitions of life. Origin of Life and Evolution of Biosfere 28(4-6): 6I3-622, I998.

MacARTHUR, R.H. Population ecology of some warbles species of northeastern coniferous forest. Ecology 39: 599-56I, I958.

MARTINI, B; RIBEIRO, C. G. Antropoceno: a época da humanidade? Ciência Hoje 283: 38-42, 20 II.

MARTINS, R. P. Teorias. In: MARTINS, R. P.; MARI, H. (eds). Universos do conhecimento. Belo

Horizonte, Editora Faculdade de Letras da UFMG, 2002, p. 9I-II5.

MOROWITZ, H. J. The emergence of everything - How the world become complex. Oxford, Oxford University Press, 2002, 209 p.

MITTERMAYER, R. Megadiversity: Washington D.C. Earth's Biologically Wealthiest Nations. Conservation International, I998.

NAEEM, S. Species redundancy and ecosystem reabilitiy. Conservation Biology 1998 v. 12 n.1, p. 39-45.

OLIVEIRA, A. L. Universo. In: MARTINS, R. P.; MARI, H. (eds). Universos do Conhecimento. Belo Horizonte, Editora Faculdade de Letras da UFMG, 2002, p. II7-I48.

PAINE, R.T. Food web complexity and species diversity. American Naturalist. I966. v. Ioo, n. 9I0, p. 65-75.

PICKETT, S. T. A. et al. Ecological Understanding: the nature of Theory and The theory of Nature. Elsevier, New York, 2007.

PRICE, P. W. Species interactions and the evolution of biodiversity. In C. M. HERRERA and O. PELLMYR, eds. Plant-animal interactions: an evolutionary approach. Oxford, Blackwell Science, 2002. p. 3-25.

ROBERTS, A. Evolution - The human story. London, Dorling Kindersley Limited, 20 II.

SUGIHARA, G.; MAY, R. M. Applications of fractals in ecology. Trends in Ecology \& Evolution. I990, v. 5, p. 79-86.

THOMPSON, J. N. The role of coevolution. Science, 20I2. v . 335, p.4IO-4II.

WEISS, K. et al. How are we made? Evolutionary Anthropology 20I5, v. 24, p. 130-136.

WRAY, G.A et al. Comments. Nature 20I4, v. 5I4, p. I6I-I64.

ZARET, T.; PAINE, R. T. Species introduction in a tropical lake. Science I973, v. I82, p.449-455. 